\title{
Attributions to Success and Failure in English Language Learning: A Comparative Study of Urban and Rural Undergraduates in Malaysia
}

\author{
Peter Gobel ${ }^{1}$, Siew Ming Thang ${ }^{2}$, Gurnam Kaur Sidhu', Sok Imm Oon ${ }^{4} \&$ Yuen Fook Chan $^{3}$ \\ ${ }^{1}$ Kyoto Sangyo University, Japan \\ ${ }^{2}$ Universiti Kebangsaan Malaysia, Malaysia \\ ${ }^{3}$ Universiti Teknologi MARA, Malaysia \\ ${ }^{4}$ Universiti Sains Malaysia, Malaysia \\ Correspondence: Siew Ming Thang, School of Linguistics and Language Studies, The National University of \\ Malaysia, Bangi, 43600 UKM Bangi, Selangor, Malaysia. Tel: 60-3-8921-6499. E-mail: thang@ukm.my
}

\author{
Received: November 7, 2012 Accepted: December 5, 2012 Online Published: January 28, 2013 \\ doi:10.5539/ass.v9n2p53 \\ URL: http://dx.doi.org/10.5539/ass.v9n2p53
}

\begin{abstract}
This paper presents a descriptive study of Malaysian urban and rural students' attributions for success and failure in learning English as a second language. Data was collected using the Attribution to Success and Failure Questionnaires (ASQ \& AFQ), based on previous research conducted by Vispoel and Austin (1995). The findings indicated that urban and rural students held different attribution ratings for the success and failure for learning English as a second language with the urban group being more willing to attribute success to their own ability, effort, and study skills than the rural group. Based on this data, we can hypothesize that the urban group are much more study-wise and confident as they have a greater belief in their own ability to take control of their successes in the language classroom.
\end{abstract}

Keywords: attribution to success and failure, English learning, urban and rural students

\section{Introduction}

Attribution is primarily the process of assigning a cause to an event or clarifying the event (Malle, 2001). That individuals ascribe reasons and explanation for why they succeed or fail at a task is not surprising considering that they attempt to make sense of observed events to increase their understanding of observed behavior and to increase their ability to predict the course of similar future behaviour (Shaver, 1975). Weiner $(1986,2000)$ states that attributions come from a person's self-perceptions and can influence their expectancy, values, emotions, and beliefs about their competence, and in turn influence their motivation. Similarly, Frieze (1981) adds that people's beliefs about the causes of their success and failure influence their motivation for learning.

Attribution theory was developed over time by several social psychologists, including Heider (1958), Jones and Davis (1965), and Kelley (1967). This led to further research on achievement behaviour through analyzing attributions for success or failure (Weiner, Frieze, Kukla, Ried, Rest, \& Rosenbaum, 1971; Burke, 1978; Elig \& Frieze, 1979; Weiner, 1979). When one succeeds, one normally ascribes one's success to an internal factor, e.g., "I did it because I am skillful". However, when a rival succeeds, one tends to credit an external factor which caused him to succeed, e.g. luck. When we fail or make mistakes, we are more likely to use external attributions, attributing causes to situational factors rather than blaming ourselves. When others fail or make mistakes, internal attributions are often used, saying it is due to reasons such as lack of ability, or lack of effort (Zuckerman, 1971).

A three-stage process characterizes attribution; behavior must be observed, this behavior is determined to be intentional and is attributed to internal or external causes. Weiner (1986) described the attributions or explanations subjects give for their success or failure along the three causal dimensions of locus, stability, and control. Whether subjects perceived their successes or failures as internal or external, stable or unstable, controllable or uncontrollable are important (Weiner, 1992). These three dimensions are used in parallel by researchers with the four factors of ability, effort, luck, and task ease or difficulty (e.g. Bruning, Schraw \& Ronning, 1999; Dörnyei \&Murphey, 2003; Hsieh \& Schallert, 2008; Weiner et al., 1971). Locus refers to the location, internal or external, of the perceived cause of a success or failure. Ability is perceived as internal while 
luck is external. Stability refers to how much a given reason for success or failure could be expected to change, i.e., whether a cause is stable (fixed) or unstable (variable) over time. Ability is seen as stable (fixed) while effort is unstable (variable). Control indicates how much control the individual has over a cause. It distinguishes causes one can control, such as skill/efficacy, from causes one cannot control, such as aptitude, mood, others' actions and luck. Table 1 shows how the attributions of ability, effort, luck and task can be integrated in terms of the dimensions of locus, stability and control.

Table 1. Dimensional classification scheme for causal attributions

\begin{tabular}{llll}
\hline Attribution & $\begin{array}{l}\text { Dimension } \\
\text { Locus }\end{array}$ & Stability & Controllability \\
\hline Ability & Internal & Stable & \\
Effort & Internal & Unstable & Uncontrollable \\
Strategy & Internal & Unstable & Controllable \\
Interest & Internal & Unstable & Controllable \\
Task difficulty & External & Stable & Controllable \\
Luck & External & Unstable & Uncontrollable \\
Family influence & External & Stable & Uncontrollable \\
Teacher influence & External & Stable & Uncontrollable \\
\hline
\end{tabular}

Source: Adapted from Vispoel and Austin (1995), based on Weiner (1979).

Research has shown that attributions of causality vary depending on the person, the task, the culture and the social group (Graham, 1991). Variations in attributions have been reported for gender (Nelson \& Cooper, 1997; Pintrich \& Schunk, 2002), with women being seen as more likely than men to attribute success to something other than themselves (Fox \& Fern, 1992). In addition, Hispanic women are more likely to attribute job performance to something other than personal ability than are non-Hispanic women (Romero \& Garza, 1986). Variations in attributions have also been reported for self-esteem (Betancourt \& Weiner, 1982; Fitch, 1970; Skaalvik, 1994), perceived intelligence (Swami \& Furnham, 2010; Kudnra, Furnham \& Swami, 2010), performance (Carr \& Borkowski, 1989; Kristner, Osborne, \& LeVerrier, 1988), and for social position with members of minority ethnic groups being more likely to believe that success and failure result from social position or luck (Kluegel \& Smith, 1986).

\section{Attribution Theory and Language Learning}

Even though attribution theory is important in educational contexts, there have not been many studies on the theoretical significance of attribution in the area of motivation of Second Language (L2) learners. In Horwitz's (1988) study, learning a foreign language was perceived to be a difficult task by students whose assumptions about who could succeed at it affected their expectations of success and their motivation. It is also associated with risking embarrassment and losing face (Horwitz, 1990).

Some studies have shown that attributions for language learning may be very different from those of other areas of learning where attributions of success are often perceived as internal while attributions for failure are seen as external. For example, British primary school children attributed success to external factors, in particular, teacher influence (French, Williams \& Burden, 1999) and Tse's (2001) American undergraduate and graduate foreign language students attributed their success in foreign language learning to several external factors, for example, their teachers, the classroom environment, family and community assistance, though in mixed-level classes, one external factor was cited as an attribution for failure.

There are studies in which success was attributed to internal factors (Fisher, 2001; Graham, 2002; Williams, Burden \& Al-Baharna, 2001). In the latter study, two internal factors, practice and a positive attitude, and one external factor, support from family were cited as attributions for success. It is also noted that the respondents, who were students learning English in Bahrain, attributed failure to mainly external attributions, for example, teaching methods, lack of support from family and teachers, poor comprehension and negative attitude. William, Burden, Poulet, and Maun (2004) found that the majority of attributions for both success and failure in their study were internal and that the variables of gender, year group and language studied showed clear differences in attribution for success and failure. Ushioda (2001) found that respondents who were university French learners attributed success to internal locus while attributions for failure were external. In contrast, Gobel and Mori (2007) 
discovered that first-year Japanese undergraduates in speaking and reading classes attributed success to teachers and the classroom environment while attributing failure to internal factors of lack of ability and lack of effort. This is a possible reflection of culture on attributions of success and failure. Similar findings were found in subsequent studies by Gobel et al. (2011) when they compared Thai, Japanese and Malaysian undergraduates, and by Thang et al. (2011) when they compared the undergraduates in six Malaysian universities. However, Mori et al. (2011) found that high proficiency Malaysian undergraduates and those who perceived themselves as such were more similar to students in western contexts as they attributed success to their own effort and ability and failure to class and interest-related factors such as class atmosphere and interest in the task.

In a study carried out in Pakistan (Adiba, 2004), high achievers attributed their success and failures to their ability and effort and low achievers attributed their success and failures to task difficulty and lack of ability or luck. There was no significant difference between urban and rural students with regard to their successes and failures. In fact, there is very little literature on comparing the attributions of success and failure of urban and rural students in the learning of English. In view of that we feel that a study that undertakes this aspect will be timely and that is the focus of this research study.

\section{The learning of English in the Urban and Rural Areas in Malaysia}

The learning of English in rural schools in Malaysia has always been a major problem for educators as they struggle to pull proficiency levels up against a backdrop where the language is almost non-existent other than the few periods of English per week for learners where English is viewed as a foreign language (Thiyagarajah, 2003). It is a language that is not spoken or heard of at home nor in school or the social environment. Therefore, teaching and learning the language comes with an almost 'innate' set of obstacles. The falling standard of English remains till this day, an extremely heated topic, with politicians and the public hotly debating whether to strengthen the teaching of English or teaching Science and Mathematics in English, despite the decision of the government to revert back to the previous policy of teaching these two subjects in the national language, Bahasa Malaysia. Gaudart (1987:17) could not have expressed it better when she said that, "Malaysian society is constantly regaled with opinions about the falling standards of English. Falling where and in what way is seldom mentioned."

According to Edwin and Talif (1990), rural schools play a major role in the high failure rate of the Sijil Rendah Peperiksaan (SRP) or Lower Secondary Examination English subject. The majority of the students in the rural schools were in the credit and pass levels whereas the majority of the urban students were in the distinction and credit levels. The difference in achievement levels is a strong indicator of the difference in proficiency levels between urban and rural youths and further highlights the disparity in the urban-rural divide.

Recent research in this area has uncovered urban/rural and class differences in self-perception of intelligence, and differences in educational goals and academic achievement. Swami and Furnham (2010) found in a nation-wide study of self-assessed intelligence, that urban participants tended to have higher self assessments than their rural counterparts. Kudrna et al. (2010) found parallel results regarding the connection between social class and self-assessed intelligence, with participants of a high social class having significantly higher self-assessments when their social class was salient. Baharudin, Chi Yee, Sin Jing, and Zulkefly (2010) found that academic goals and academic achievement also varied based on location. These recent studies suggest that there may be some sort of urban/rural divide that may explain the results.

Urban students come from an environment where they are in frequent contact with English and many of them come from affluent homes where English is used. Rural students, however, are in an environment where English is a foreign language and they have practically zero opportunity to practice it as their peers are also facing the same predicament, their parents are not educated enough to give them the necessary educational support and their families' socioeconomic status do not allow them easy access to books, CD's, and even television in some cases. Due to this lack of exposure to English, they may lack self-esteem, have low confidence and very likely suffer from low motivational levels.

Given this landscape, the question of interest is, whether these two groups of students have similar attribution to success and failure. Thus, this research study is guided by the following research questions:

1) To what dimensions proposed by attribution theory do urban Malaysian university students attribute their success and failure?

2) To what dimensions proposed by attribution theory do rural Malaysian university students attribute their success and failure?

3) To what extent are these attributions of success and failure different? 
4) What is the role of proficiency levels on these attributions of success and failure?

\section{Research Methodology}

A descriptive research approach was adopted to allow a quantitative description of the attributions to success and failure in English Language Learning among urban and rural students in Malaysia. According to Cohen, Marion \& Morrison (2003) a descriptive study describes the current status of subjects in a study in a clear and concise manner. Descriptive research was conducted to identify variables that can be later studied in depth. Rama, Yoder \& Ewing (2007: 692-693) further elaborated that, "the goal of descriptive research is to portray accurately the incidence, distribution, and characteristics of a group or situation. In essence, it describes "what is" of the group or situation. In this descriptive research, variables of attribution success and failure are examined to describe two categories of students: urban and rural.

\subsection{Sample Population}

This study involved respondents from the six main public universities in Malaysia - i.e. University Malaya (UM), Universiti Kebangsaan Malaysia (UKM), Universiti Sains Malaysia (USM), Universiti Putra Malaysia (UPM), Universiti Teknologi MARA (UiTM), and Universiti Malaysia Sabah (UMS). These respondents were second, third and fourth semester university students who were non-English majors and were learning English as a second language. A simple random sampling procedure was employed. A total of 1,156 students were involved in the study. A total of 548 students responded to the Attitude towards Successful Activity (ASQ) questionnaires whilst the remaining 557 students answered the Attitude towards Failure (AFQ) questionnaires.

Since the primary purpose of this study is to investigate the influence of the rural/urban divide on attributions for success and failure, the students were classified into two groups - the urban and rural groups - based on their locality in the last year of their primary schools. This was decided to be the most reliable measure of locality in view of the fact that many rural students who performed well in their Primary School Assessment Test (undertaken in Primary six) were transferred to residential secondary schools.

The respondents' English language proficiency measured using the Sijil Peperikasaan Malaysia (SPM)/(Malaysian Certificate of English), which is a Public Examination taken by students upon completion of their Secondary school education, indicated that the urban students in both the ASQ and AFQ groups scored higher than rural students in general. For this reason, test score was deemed a necessary covariate for this study. Table 2 showed the SPM Scores of both groups of students. For this study, students scoring A1-A2 and B3-B4 are classified as high SPM group and students scoring C5-C6, P7-P8 and F9 are classified as low SPM group.

Table 2. SPM scores as percentages by group

\begin{tabular}{llll}
\hline ASQ group & Total \% & Urban \% & Rural \% \\
\hline A1 - A2 (Distinction) & 0.33 & 0.42 & 0.19 \\
B3 - B4 (Strong Credits) & 0.31 & 0.36 & 0.23 \\
C5 - C6 (Weak Credits) & 0.23 & 0.14 & 0.36 \\
P7 - P8 ( Pass) & 0.13 & 0.07 & 0.21 \\
F9 (Fail) & 0.00 & 0.00 & 0.01 \\
& 1.00 & 1.00 & 1.00 \\
AFQ group & & & \\
A1 - A2 (Distinction) & 0.33 & 0.46 & 0.18 \\
B3 - B4 (Strong Credits) & 0.25 & 0.24 & 0.26 \\
C5 - C6 (Weak Credits) & 0.23 & 0.21 & 0.24 \\
P7 - P8 ( Pass) & 0.18 & 0.08 & 0.29 \\
F9 (Fail) & 0.02 & 0.01 & 0.02 \\
& 1.00 & 1.00 & 1.00 \\
\hline
\end{tabular}

Note: A1-A2 is the highest level, with F9 being a failing score

\subsection{Measures}

The study employed two main sets of self-administered questionnaires- i.e. Attribution Success Questionnaire (ASQ) and Attribution Failure Questionnaire (AFQ). Both questionnaires consisted of two main sections. The 
first section investigated the demographic profile of the respondents. The aspects explored included variables such as gender, ethnicity, year of study and their language achievement in Malaysian public examinations such as the SPM and MUET English test. Respondents were also required to self-rate their proficiency in English and identify the location of their school where they had their primary, lower secondary, upper secondary and pre-university education. The second section consisted of questions relating to reasons why students did well or did not do well in the English language classroom activities. The respondents were required to provide their responses based on a six-point Likert scale ranging from strongly agree to strongly disagree (see Appendix A for the questionnaire). The quantitative data was analyzed using inferential statistics.

\subsection{Procedure}

Students from the six universities were asked to fill in either the ASQ or the AFQ. A roughly equal number of ASQ and AFQ were distributed in each university in such a manner as to produce a fairly even distribution of sample population in terms of proficiency levels and students' major disciplines. The questionnaire was completed within 15 to 20 minutes. The quantitative data was analysed by using the SPSS package (version 18.0).

\section{Results}

\subsection{Differences in Attribution Tendencies}

In order to determine the extent to which attribution ratings varied with respect to urban/rural divide, a factor analysis was first performed to reduce the measured variables to a smaller set of factors. If the dimensions suggested by attribution theory actually exist, those attributions that are categorized as internal/unstable/controllable should load together as a result of factor analysis.

The dimensionality of the 12 items from the success attribution measure was analyzed using principal components analysis. Four criteria were used to determine the number of factors to rotate: a minimum eigenvalues of 1.0, the scree test, a minimum loading of .45, and the interpretability of the factor solution. Based on these criteria, three factors were rotated using a Varimax rotation procedure. The rotated solution, as shown in Table 3, yielded three interpretable factors, an internal/controllable success attribution, a class and interest-related success attribution, and a task difficulty-related external/uncontrollable success attribution. The internal/controllable success attribution accounted for $35.56 \%$, class and interest-related success attribution accounted for $11.34 \%$, and task difficulty-related external/uncontrollable success attribution accounted for $9.07 \%$ of the item variance.

Table 3. Principal components results for success $(\mathrm{n}=548)$

\begin{tabular}{llllllll}
\hline & \multicolumn{4}{c}{ Dimension } & \multicolumn{5}{c}{ Component } \\
Variables & Locus & Stability & Controllability & 1 & 2 & 3 & $h^{2}$ \\
\hline Ability & Internal & Stable & Uncontrollable & $\mathbf{0 . 6 7 8}$ & -0.016 & 0.316 & 0.554 \\
Effort & Internal & Unstable & Controllable & $\mathbf{0 . 6 6 1}$ & 0.180 & 0.001 & 0.483 \\
Strategy & Internal & Unstable & Controllable & $\mathbf{0 . 8 0 0}$ & 0.091 & 0.008 & 0.652 \\
Preparation & Internal & Unstable & Controllable & $\mathbf{0 . 6 8 4}$ & 0.316 & 0.053 & 0.569 \\
Enjoyment & Internal & Stable & Controllable & $\mathbf{0 . 5 7 2}$ & 0.430 & 0.143 & 0.530 \\
Interest & Internal & Unstable & Controllable & 0.476 & $\mathbf{0 . 5 1 6}$ & 0.143 & 0.516 \\
Level & External & Stable & Uncontrollable & 0.204 & $\mathbf{0 . 7 0 5}$ & 0.211 & 0.588 \\
Teacher & External & Stable & Uncontrollable & 0.047 & $\mathbf{0 . 7 8 3}$ & 0.147 & 0.626 \\
Class & External & Stable & Uncontrollable & 0.130 & $\mathbf{0 . 7 3 1}$ & 0.193 & 0.586 \\
Grade & Internal & Stable & Controllable & 0.207 & $\mathbf{0 . 5 7 7}$ & -0.097 & 0.397 \\
Task & External & Stable & Uncontrollable & 0.124 & 0.161 & $\mathbf{0 . 7 6 9}$ & 0.637 \\
Luck & External & Unstable & Uncontrollable & 0.070 & 0.124 & $\mathbf{0 . 7 6 0}$ & 0.622 \\
\hline
\end{tabular}

Using the same criteria, the dimensionality of the 12 items from the failure attribution measure was analyzed. The rotated solution, as shown in Table 4, yielded three interpretable factors, class and interest-related failure attribution, internal/controllable failure attribution, and task-related failure attribution. Class and interest-related failure attribution accounted for $38.06 \%$, internal/controllable failure attribution accounted for $13.44 \%$, and task-related failure attribution accounted for $9.06 \%$ of the item variance. 
Table 4. Principal components results for failure $(n=557)$

\begin{tabular}{llllllll}
\hline & \multicolumn{3}{c}{ Dimension } & \multicolumn{4}{c}{ Component } \\
Variables & Locus & Stability & Controllability & 1 & 2 & 3 & $h^{2}$ \\
\hline Interest & Internal & Unstable & Controllable & 0.527 & 0.389 & 0.160 & 0.455 \\
Luck & External & Unstable & Uncontrollable & 0.557 & 0.120 & 0.294 & 0.411 \\
Teacher & External & Stable & Uncontrollable & 0.814 & 0.000 & 0.147 & 0.684 \\
Class & External & Stable & Uncontrollable & 0.738 & 0.036 & 0.252 & 0.609 \\
Grade & Internal & Stable & Controllable & 0.788 & 0.157 & -0.289 & 0.729 \\
Enjoyment & Internal & Stable & Controllable & 0.763 & 0.313 & -0.052 & 0.683 \\
Level & External & Stable & Uncontrollable & 0.808 & 0.182 & 0.051 & 0.688 \\
Effort & Internal & Unstable & Controllable & 0.236 & 0.763 & -0.171 & 0.666 \\
Strategy & Internal & Unstable & Controllable & 0.196 & 0.614 & 0.258 & 0.483 \\
Preparation & Internal & Unstable & Controllable & 0.167 & 0.752 & 0.019 & 0.593 \\
Ability & Internal & Stable & Uncontrollable & -0.112 & 0.579 & 0.352 & 0.471 \\
Task & External & Stable & Uncontrollable & 0.192 & 0.139 & 0.860 & 0.795 \\
\hline
\end{tabular}

A one-way multivariate analysis of covariance (MANCOVA) was performed to determine the effect of the independent variable of urban/rural divide using the SPM scores as a covariate. Only Factor 1 was significant for the independent variable, $F(1,545)=5.19, p=.02$, and for proficiency, $F(1,545)=10.88, p<.00$. Looking at the means for the factor scores (in Table 5), we can see that the urban group and the SPM high group both had a more positive view of this factor than the rural group, suggesting that they attribute internal/controllable attributes to their success more than the rural group. In other words, when they succeeded, they were more likely to attribute this to the dimensions in Factor 1 (Ability, Effort, Study Strategy, and Preparation).

Table 5. Means factor scores for success

\begin{tabular}{llll}
\hline Factors & $N$ & Mean & Std Deviation \\
\hline Factor 1 & 548 & & \\
Urban & 342 & 0.118 & 0.983 \\
Rural & 206 &.-0.206 & 1.01 \\
SPM high & 357 & 0.133 & 0.9585 \\
SPM low & 191 & -0.196 & 0.9995 \\
Factor 2 & 548 & & \\
Urban & 342 & -0.028 & 0.971 \\
Rural & 206 & 0.047 & 1.047 \\
SPM high & 357 & -0.034 & 0.979 \\
SPM low & 191 & 0.064 & 1.038 \\
Factor 3 & 548 & & \\
Urban & 342 & 0.068 & 0.997 \\
Rural & 206 & -0.113 & 0.998 \\
SPM high & 357 & 0.025 & 0.972 \\
SPM low & 191 & -0.047 & 1.051
\end{tabular}

A MANCOVA was also performed to determine the effect of locality and SPM proficiency scores on the three failure attributional factors measured by factor scores. Differences were significant for Factor 1 and Factor 2 for the SPM independent variable: $F(1,554)=10.26, p<.00$; and $F(1,554)=4.02, p=.04$ respectively, indicating a significant difference in the way the two groups attribute their failures at language tasks. However, for the urban/rural independent variable, Factor 3 was significant at $F(1,554)=9.69, p=.02$. 
Table 6. Mean factor scores for failure

\begin{tabular}{llll}
\hline Factors & $N$ & Mean & Std Deviation \\
\hline Factor 1 & 557 & & \\
Urban & 307 & 0.109 & 1.061 \\
Rural & 250 & -0.134 & 0.904 \\
SPM high & 334 & 0.132 & 1.057 \\
SPM low & 233 & -0.198 & 0.872 \\
Factor 2 & 557 & & \\
Urban & 307 & -0.099 & 0.976 \\
Rural & 250 & 0.121 & 1.018 \\
SPM high & 334 & -0.091 & 0.983 \\
SPM low & 233 & 0.137 & 1.012 \\
Factor 3 & 557 & & \\
Urban & 307 & -0.137 & 0.947 \\
Rural & 250 & 0.168 & 1.039 \\
SPM high & 334 & -0.051 & 0.981 \\
SPM low & 233 & 0.076 & 1.026 \\
\hline
\end{tabular}

Referring to the mean factor scores in Table 6, it is evident that for Factor 1 (class/interest-related) the high SPM group more frequently attributed failure to this factor than the low SPM group. For Factor 2 (internal/controllable), the low SPM group tended to attribute their lack of ability and effort to their failures more than the high SPM group did. Finally, for Factor 3 (Task), the rural group tended to attribute failure to the kind of task they were given, more frequently than the urban group did. So we see a number of really clear differences in both success attributions and failure attributions.

\section{Discussion of Findings}

To summarize, with regard to success attributions, the findings reveal that there is a significant difference between the mean scores of the urban and rural groups for Factor 1 (internal/ controllable attributes). Thus, it would seem that the urban group is more willing to attribute success to their own ability, effort, and study skills than the rural group. This is a poignant finding as it suggests a propensity for the urban students to believe in their own abilities when they succeed. In the case of failure attribution, there are no significant differences between the mean scores of the urban and rural groups for both Factor 1 (class/interest-related attributes) and Factor 2 (internal/controllable attributes). However, interestingly, the rural group seems to attribute failure more to the task they are given. Based on this data, we can hypothesize that the students in the urban group are more study-wise and confident as they have a greater belief in their own ability to take control of their successes in the language classroom.

The findings based on the SPM results suggest that the high SPM group is more likely to attribute their success to their own ability, effort, and study skills and their failure to class/interest-related factors than the low SPM group. On the other hand, the low SPM group tended to attribute their lack of ability and effort to their failures more than the high SPM group. Thus, it is evident that the high SPM group believes more in their own ability to determine success and has the tendency to blame uncontrollable factors for their failure.

The findings clearly indicate a close correlation between the attributions to success of the urban group and the high proficiency group. This is not surprising as the statistics show that majority of the high proficient students are from the urban group. Thus the conclusion that we can arrive at is that confidence and positive attitudes towards learning English comes with high proficiency and not so much as where one comes from. In view of that it is essential to provide rural students with a more conducive environment to improve their English.

At this juncture it is pertinent to look into the pedagogical implications of this study and seek ways in which rural students can be helped to improve language proficiency. This would perhaps help them to be positively motivated and confident like their urban counterparts to take charge of their own learning. To realize this, teachers must first ensure that sufficient language input is provided during listening and reading classes so that students will be confident enough to produce language expected in the speaking and writing classes. For instance, 
Ratnawati \& Ismail (2003) highlighted that rural students can benefit from extensive reading programmes. Their findings indicated that a majority of their rural school respondents under their extensive reading programme shifted from initially reluctant readers to develop positive attitudes towards reading in English and enhancing language proficiency.

\section{Conclusion}

To conclude it cannot be stressed enough that whatever strategies used, the rural ESL classrooms must be student-centered, providing students with ample opportunities to use the language. More importantly, teachers must be creative enough to ensure that learning of English is meaningful, fun and stimulating. Once students are engaged they will be more willing to take responsibility for their own learning, putting them on the path to becoming self-motivated autonomous learners.

\section{References}

Adiba, F. (2004). Study of attributions of low achievers and high achievers about the perceived causes of their success and failure. Ph.D thesis, University of Arid Agriculture, Rawalpindi. Retrieved from http://eprints.hec.gov.pk/578/

Baharudin, R., Chi Yee, H., Sin Jing, L., \& Zulkefly, N. (2010). Educational goals, parenting practices and adolescents' academic achievement. Asian Social Science, 6(12), 144-152.

Betancourt, H., \& Weiner, B. (1982). Attributions for achievement-related events, expectancy and sentiments: A study of success and failure in Chile and the U.S. Journal of Cross Cultural Psychology, 13, 263-374. http://dx.doi.org/10.1177/0022002182013003007

Bruning, R. H., Schraw, G. J., \& Ronning, R. R. (1999). Cognitive psychology and instruction (3rd ed.). Upper Saddle River, N J: Merrill.

Burke, J. P. (1978). On causal attribution: The interactive relationship between self-esteem and task performance. Social Behavior and Personality, 6, 211-221. http://dx.doi.org/10.2224/sbp.1978.6.2.211

Carr, M., \& Borkowski, J. G. (1989). Attributional retraining and the generalization of reading strategies by underachievers. Human Learning and Individual Differences, 1, 327-341. http://dx.doi.org/10.1016/1041-6080(89)90015-0

Cohen, L., Manion, L., \& Morrison, K. (2003). Research methods in education. New York: Routledge/Falmer.

Dörnyei, Z., \& Murphey, T. (2003). Group dynamics in the language classroom. Cambridge: Cambridge University Press. http://dx.doi.org/10.1017/CBO9780511667138

Edwin, M., \& Talif, R. (1990). A comparative study of the achievement and the proficiency levels in English as a second language among learners in selected rural and urban schools in Peninsular Malaysia. The English Teacher, 19, 48-57.

Elig, T., \& Frieze, I. (1979). Measuring causal attributions for success and failure. Journal of Personality and Social Psychology, 37, 621-634. http://dx.doi.org/10.1037/0022-3514.37.4.621

Fitch, G. (1970). Effects of self-esteem, perceived performance, and choice on causal attributions. Personality and Social Psychology, 16, 311-315. http://dx.doi.org/10.1037/h0029847

Fox, \& Fern. (1992). quoted in Lovaglia, M. J. (2007). Knowing People: the personal use of social psychology (2nd ed.). Maryland: Rowman and Littlefield Publishers.

Frieze, I. H. (1981). Children's attributions for success and failure. In S. S. Brehm, S. M. Kassin, \& F. X. Gibbons (Eds.), Developmental social psychology: Theory and research (pp. 51-71). New York: Oxford University Press.

Gaudart, H. (1987). English language teaching in Malaysia: A historical account. The English Teacher, 16, 17-36.

Gobel, P., \& Mori, S. (2007). Success and failure in the EFL classroom: Exploring students' attributional beliefs in language learning. Euro SLA Yearbook, 7, 149-169. http://dx.doi.org/10.1075/eurosla.7.09gob

Gobel, P., Mori, S., Thang, S. M., Kan, N. H., \& Lee, K. W. (2011). The impact of culture on student attributions for performance: A comparative study of three groups of EFL/ESL learners. Journal of Institutional Research (South East Asia)(JIRSEA), 9(1), 27-43.

Graham, S. (1991). A review of attribution theory in achievement contexts. Educational Psychology Review, 3, 
5-39. http://dx.doi.org/10.1007/BF01323661

Heider, F. (1958). The psychology of interpersonal relations. New York: John Wiley and Sons. http://dx.doi.org/10.1037/10628-000

Hsieh, P., \& Schallert, D. L. (2008). Implications from self-efficacy and attribution theories for an understanding of undergraduates' motivation in a foreign language course. Contemporary Educational Psychology, 33(4), 513-532. http://dx.doi.org/10.1016/j.cedpsych.2008.01.003

Jones, E. E., \& Davis, K. E. (1965). From acts to dispositions: The attribution process in person perception. In L. Berkowitz (Ed.), Advances in experimental social psychology (pp. 219-266). New York: Academic Press.

Kelley, H. (1967). Attribution theory in social psychology (Ed.). Nebraska symposium on Motivation. Lincoln: University of Nevada Press.

Kristner, J., Osborne, M., \& Leverrier, L. (1988). Causal attributions of LD children: Developmental patterns and relation to academic progress. Journal of Educational Psychology, 80, 82-89. http://dx.doi.org/10.1037/0022-0663.80.1.82

Kudrna, L., Furnham, A., \& Swami, V. (2010). The influence of social class salience on self-assessed intelligence. Social Behavior \& Personality: An International Journal, 38(6), 859-864. http://dx.doi.org/10.2224/sbp.2010.38.6.861

Lovaglia, M. J. (2007). Knowing People: The personal use of social psychology (2nd ed.). Maryland: Rowman and Littlefield Publishers.

Malle, B. F. (2001). Attribution processes. In N. J. Smelser, \& P. B. Baltes (Eds.), International encyclopedia of the social and behavioral sciences 14, Developmental, social, personality, and motivational psychology, (section editor N. Eisenberg, pp. 913-917). Amsterdam: Pergamon/Elsevier.

Mori, S., Thang, S. M., Nor, F. M. N., Vijaya, L. S., \& Oon, S. I. (2011). Attribution tendency and its relationship with actual and perceived proficiency. GEMA Online Journal of Language Studies, 11(3), 199-218.

Nelson, L. J., \& Cooper, J. (1997). Gender differences in children's reactions to success and failure with $\begin{array}{lllll}\text { computers. } \quad \text { Computers Hehaviour, } & \text { 12, 247-267. }\end{array}$ http://dx.doi.org/10.1016/S0747-5632(97)00008-3

Pintrich, P. R., \& Schunk, D. (2002). Motivation in education: Theory, research, and application (2nd ed.). Upper Saddle River, NJ: Prentice-Hall.

Ratnawati, M. A., \& Ismail, S. A. (2003). Promoting English language development and the reading habit among students in rural schools through the guided extensive reading program. Reading in a Foreign Language, 15(2), 83-102.

Romero, G. J., \& Garza, R. T. (1986). Attributions for the occupational success/failure of ethnic minority and non-minority women. Sex Roles, 14(7), 445-452. http://dx.doi.org/10.1007/BF00288426

Shaver, K. G. (1975). An introduction to attribution processes. Cambridge: Winthrope Publishers.

Skaalvik, E. (1994). Attribution of perceived achievement in school in general and in math and verbal areas: relations with academic self-concept and self-esteem. British Journal of Educational Psychology, 64, 133-143. http://dx.doi.org/10.1111/j.2044-8279.1994.tb01090.x

Swami, V., \& Furnham, A. (2010). Self-assessed intelligence: Inter-ethnic, rural-urban, and sex differences in Malaysia. Learning \& Individual Differences, 20(1), 51-55. http://dx.doi.org/10.1016/j.lindif.2009.11.002

Thang, S. M., Gobel, P., Nor F. M. N., \& Vijaya L. S. (2011). Students' attributions for success and failure in the learning of English as a second language: A comparison of undergraduates from six public universities in Malaysia. Pertanika Journal of Social Sciences \& Humanities, 19(2), 459-474.

Thiyagarajah, P. M. (2003). Learning English in Malaysian rural secondary schools: Difficulties, learning styles \& strategies and motivation. Retrieved http://lc03.commongroundconferences.com/ProposalSystem/Presentations/P000844.html.

Tse, L. (2000). Student perceptions of foreign language study: A qualitative analysis of foreign language autobiographies. The Modern Language Journal, 84, 69-84. http://dx.doi.org/10.1111/0026-7902.00053

Ushioda, E. (2001). Language learning at university: Exploring the role of motivational thinking. In Z. Dörnyei, \& R. Schmidt (Eds.), Motivation and second language acquisition (pp. 93-126). Honolulu: University of Hawaii. 
Vispoel, W., \& Austin, J. (1995). Success and failure in junior high school: A critical incident approach to understanding students' attributional beliefs. American Educational Research Journal, 32(2), 377-412.

Weiner, B. (1979). A theory of motivation for some classroom experiences. Journal of Educational Psychology, $71,3-25$.

Weiner, B. (1986). An attributional theory of motivation and emotion. New York: Springer Verlag. http://dx.doi.org/10.1007/978-1-4612-4948-1

Weiner, B. (1992). Human motivation: Metaphors, theories and research. Newbury Park, Ca: SAGE.

Weiner, B. (2000). Intrapersonal and interpersonal theories of motivation from an attributional perspective. Educational Psychology Review, 12, 1-14. http://dx.doi.org/10.1023/A:1009017532121

Weiner, B., Frieze, I., Kukla, A., Reed, L., Rest, S., \& Rosenbaum, R. (1971). Perceiving the causes of success and failure. Morristown, NJ: General Learning Press. http://dx.doi.org/10.1037/0022-0663.71.1.3

Williams, M., Burden, R., \& Al-Baharna, S. (2001). Making sense of success and failure: The role of the individual in motivation theory. In Z. Dörnyei, \& R. Schmidt (Eds.), Motivation and second language acquisition (pp. 171-184). Honolulu: University of Hawaii.

Williams, M., Burden, R., Poulet, G., \& Maun, I. (2004). Learners' perceptions of their successes and failures in foreign language learning. Language Learning Journal, 30, 19-29. http://dx.doi.org/10.1080/09571730485200191 